\title{
THE POWER OF NUDGING FOR VIRTUAL LEARNING ENVIRONMENTS
}

\author{
T. Wernbacher ${ }^{1}$, A. Pfeiffer ${ }^{1,2,5}$, S. Kriglstein ${ }^{3,4}$, S. Bezzina ${ }^{6}$ \\ ${ }^{1}$ Donau Universität Krems (AUSTRIA) \\ ${ }^{2}$ Massachusetts Institute of Technology (UNITED STATES) \\ ${ }^{3}$ Austrian Institute of Technology (AUSTRIA) \\ ${ }^{4}$ University of Vienna (AUSTRIA) \\ ${ }^{5}$ University of Malta (MALTA) \\ ${ }^{6}$ Ministry for Education and Employment (MALTA)
}

\begin{abstract}
The term nudge or nudging originally derives from the field of behavioural economics and describes a soft type of influence with the goal to elicit a certain behaviour. Thaler \& Sunstein (1975) define nudging as a positive intervention that stimulates a voluntary change in behaviour without including external (negative) consequences. The idea of nudging has been booming in the USA for several years, while in Europe the concept of nudging remains largely unexplored. The focus is generally on the creation of politically motivated interventions and is particularly anchored in the field of health prevention (Quigley, 2013). Nudging in itself is based on motivational psychology models and shows parallels to the principle of gamification. Nudges can further be seen in a similar way to gamification, or as a relevant part of gamification, in the form of the game mechanics of achievements (Pfeiffer, 2018). However, in contrast to gamification, stimulus-response chains in the sense of incentives and penalties fade into the background and subtle strategies and positive interventions for decision optimization come to the fore. Nudging strategies have the potential to make behavioural alternatives appear more visible. For instance, in the area of physical activity, nudging can lead to the stairs becoming more attractive when compared to a lift (Hollands et al., 2013). Nudges also play a major role in (digital) game design, by for example guiding the player in the right direction or gently explaining why the player cannot choose a certain item. Furthermore, nudging can be a very effective element in the user experience design of apps by amongst others, making the user feel comfortable and ensuring that the app is used as intended (Pfeiffer, 2018). This paper aims to evaluate successful nudges from the world of games and apps and it is intended to inspire designers of virtual and blended learning systems to enhance the overall experience.
\end{abstract}

Keywords: Nudging, Behavioural Economics, learning system.

\section{INTRODUCTION}

The term nudge or nudging originally derives from the field of behavioural economics and describes a soft type of influence with the goal to elicit a certain behaviour. Thaler \& Sunstein [1] define nudging as a positive intervention that stimulates a voluntary change in behaviour without including external (negative) consequences. The idea of nudging has been booming in the USA for several years, while in Europe the concept of nudging remains largely unexplored. The focus is generally on the creation of politically motivated interventions and is particularly anchored in the field of health prevention [2]. Nudging in itself is based on motivational psychology models and shows parallels to the principle of gamification. Nudges can further be seen in a similar way to gamification, or as a relevant part of gamification, in the form of the game mechanics of achievements [3]. However, in contrast to gamification, stimulus-response chains in the sense of incentives and penalties fade into the background and subtle strategies and positive interventions for decision optimization come to the fore. Nudging strategies have the potential to make behavioural alternatives appear more visible. For instance, in the area of physical activity, nudging can lead to the stairs becoming more attractive when compared to a lift [4]. Although by Thaler \& Sunstei's definition, nudges are only to be used in a positive way, the mechanics behind nudging can be used both "for good" and "for evil". It simply always depends on who is responsible for the nudge and with what purpose the nudges were placed. But of course one can discuss whether negative nudges should also be named with the term nudge.

Digital Nudging provides digital decision environments. Design elements are mainly graphic design (such as text and colours), feedback, framing and arrangement of content. Possible applications can be 
found in the commercial sector, such as online trade, in public life (e.g. action campaigns) and party politics (e.g. election campaigns), in social media presences exemplified in the competition for attention and likes, and increasingly also in the state-regulated sector (e.g. e-government). Digital nudges are also used as "snudges", i.e. self-nudges, for example in the context of self-optimization through selftracking technologies, as an aid to adhering to medication, as a self-binding instrument to achieve selfimposed goals. In digital nudging, the focus is on the design of the user interface, which can be used either to the advantage of the user or to the advantage of the designers of the interface. [5]

Nudges also play a major role in (digital) game design, by for example guiding the player in the right direction or gently explaining why the player cannot choose a certain item. Furthermore, nudging can be a very effective element in the user experience design of gamified apps by amongst others, making the user feel comfortable and ensuring that the app is used as intended [3].

This paper aims to evaluate successful nudges from the world of games and apps and it is intended to inspire designers of virtual and blended learning systems to enhance the overall experience.

\section{METHODOLOGY}

In order to investigate the connections between Nudges, Gamification, digital games and education, the problem-centred interview following Witzel [6] was chosen. This method allows a certain freedom in the conversation despite a theory-based formulation of the questions. The answers to the questions were evaluated using the approach of qualitative content analysis according to Mayring [7]. The problemcentred interview was conducted in the form of a focus group. The focus group consisted of the following participants: a game designer, a game publisher, a game researcher, an e-learning designer, an elearning researcher, an economist and a technology researcher). The questions to the interviewees were:

- What does nudging mean to you?

- Which real world nudges do you know?

- Do you know nudges from the digital world (for example in games and/orapps) and if so, how do you describe them?

- How can digital nudges help in the educational system (such as in e-learning, blended learning, game-based learning)?

\section{RESULTS}

All participants of the focus group were familiar with the term nudges and believe that the term has become widely used, particularly as a result of the Nobel Prize won by Thaler in 2017 and the media coverage of it [8]. However, the participants are also sure that there are still people, who do not know the term or at least cannot explain it. The interviewees disagree whether the word nudge should be used for the mechanism itself or actually only for the original meaning described by Thaler \& Sunstein, i.e. to refer only to positive hints. Some of the interviewees also said that there are certainly nudges that you don't obviously recognize as such, but only when you really reflect on why you did something in particular.

Regarding real world nudges, the participants of the focus group mentioned the following situation, which they perceive as nudges:

- Speed signs with smilies for traffic control

- Smilies for rating services, e.g. at the airport

- The e-passport control at the airport, with the note that it is faster with the e-passport

- A small dish (plate) looks like a larger portion.

- A trash can that challenges you to throw the trash in

- Discounts in coffee houses if you bring the "to go" cup yourself

- Display of ecological driving in a modern hybrid car

- The colour of the traffic light (red stands for blood)

- The overall design of successful theme-parks 
In the digital field, the interviewees increasingly identified examples from the health sector and describe them as a hybrid between gamification and nudging. The apps Strava [9], Fitbit [19] or Runtastic [11] were particularly mentioned here. With this app, the design of the app itself, where the elements are placed and how they are presented is to be understood as a nudge. Nudges that are supposed to improve the user experience and guide the user through the app without having to think about it or need a manual. The App Stickk.com is also mentioned by the interviewees. On this website the user sets goals, nominates a referee, and also define the reward or punishment. This is based on the theory of Thaler \& Sunstein [1] that betting with friends is a particularly strong nudge.

Different attempts were mentioned for digital games. One approach that combines nudges with machine learning is match making in certain multi online battle arenas (like DOTA 2 [12]). Here attention is paid to the possibility that unfriendly players then also come together with other players rated as unfriendly in the free online matches. This is primarily intended to reward players who adhere to the rules to be friendly and focused. A classic design element in games are light flashing and glowing buttons. These buttons are beautifully designed and discreetly embellished, mostly by a slightly golden or red frame. These elements are used to point out game elements to the players (e.g. event days in the game) but also to boost sales in the shop. According to the focus group participants, the games Clash of Clans [13] and Pokémon go [14] are particularly good examples, according to the focus group participants. League of Legends [15] is cited as a pioneer and best practice example of nudges. In addition to the graphic design, there is also a text-nudge which is supposed to help players to be less toxic, i.e. more friendly. At the start of the game round, the loading screen indicates that friendly and helpful players are more likely to win (and the other way round that unfriendly players will more like loose). A trick that works and that can be checked out on nature.com [16].

For apps from the educational sector, mature user experience designs, or even intentional nudges are rarely used. This is due to the often very small development teams and lack of budgets. Sometimes, according to the focus group participants, there is a lack of motivation to create something great, innovative and user-centred. Instead, work packages are worked through unlovingly, simply to meet the requirements, for example, of government subsidies for the development of learning apps. An exception is the work of some studios and development teams in the field of digital game based learning. Although there are many examples that do not meet the expectations of the learners and offer a good user experience, there are, however, those which are notable exceptions. These are developments by development teams working in conjunction with game studies and e-learning departments from various universities.

The concept of nudging is also appreciable in face-to-face contexts, including in the educational and learning environments. One such example is the Quiet Light classroom noise monitor which will emit different light colours (just like a conventional traffic light) depending on the level of the noise inside the classroom (as set and programmed by the teacher). This audio-visual reminder will nudge the students' behaviour when the noise levels get too high.

\section{CONCLUSION}

Nudges can be perceived as strong mechanics to create a pleasant user experience. Nudges can also be used to alert users to specific features of the system or environment. These design or text elements can be used for good or bad purposes, with only positive nudges meeting the original definition. For digital learning experiences, it should be noted that instructional designers and learning technologists may still appear to be inexperienced in this area or may be intentionally or unintentionally not paying attention to this aspect. As a guideline for further action, the authors recommend to keep the concept of nudging in mind whilst designing digital or face-to-face learning experiences and to create training programs for those responsible for the design and development of educational software.

\section{ACKNOWLEDGEMENTS}

The authors would like to thank the participants of the focus group.

\section{REFERENCES}

[1] Thaler, R. H. \& Sunstein, C. R.: Nudge: Improving Decisions About Health, Wealth, and Happiness, 1975. 
[2] Quigley, M.: Nudging for health: On public policy and designing choice architecture. Medical Law Review, Vol. 21, Issue 4, pp. 588-621, 2013.

[3] Doctorate Alexander Pfeiffer: Approaching a ludic society; Summary of key findings and definitions, DOI: 10.13140/RG.2.2.30395.98081, 2020 DOI: 10.13140/RG.2.2.30395.98081

[4] Hollands G. J., Shemilt, I., Marteu, T. M., Jebb, S. A., Kelly, M. P., Nakamura, R. \& Ogilvie, D.: Altering micro-environments to change population health behaviour: towards an evidence base for choice architecture interventions. BMC public health, Vol. 13, Issue 1, 2013.

[5] Lucia A. Reisch, Nudging hell und dunkel: Regeln für digitales Nudging, in Wirtschaftsdienst · February 2020 DOI: 10.1007/s10273-020-2573-y, 2020

[6] Witzel, A. 2000. Das problemzentrierte Interview: http://www.qualitative-research.net/index.php/fqs/article/view/1132/2519; Accessed: January, 2020

[7] Mayring, P., Qualitative Inhaltsanalyse; Grundlagen und Techniken, Beltz Verlag, Weinheim, Basel, 2010

[8] Nobel Price official website: https://www.nobelprize.org/prizes/economic-sciences/2017/thaler/facts/, 2017 (last visited 05/05/2020)

[9] Strava official website: https://www.strava.com/ (last visited 05/05/2020)

[10] Fitbit official website: https://www.fitbit.com (last visited 05/05/2020)

[11] Runtastic official website: https://www.runtastic.com (last visited 05/05/2020)

[12] Dota2 offical website: http://de.dota2.com/?l=german (last visited 05/05/2020)

[13] Clash of Clans official website: https://supercell.com/en/games/clashofclans/ (last visited 05/05/2020)

[14] Pokemon Go official website: https://pokemongolive.com/de/ (last visited 05/05/2020)

[15] League of legends official website: https://play.euw.leagueoflegends.com/en_GB (last visited 05/05/2020)

[16] Nature.com online article on toxic players and messures taken by RIOT games: https://www.nature.com/news/can-a-video-game-company-tame-toxic-behaviour-1.19647 (last visited $05 / 05 / 2020)$ 